\title{
Devir-mar: agenciamentos na poesia portuguesa
}

\author{
Eliane Righi de Andrade* \\ Michelle Sauan**
}

\begin{abstract}
RESUMO: Este artigo discute como os portugueses são atravessados por afetos e desejos que os conectam ao mar, trazendo como exemplos algumas poesias que efetivam essa relação, em que os territórios subjetivos e geográficos são submetidos a uma (des)reterritorialização na busca de maneiras outras para se relacionarem enquanto coletividades de agenciamentos de corpos e enunciados na produção de um devir-mar.
\end{abstract}

Palavras-chave: Devir-mar; poesia portuguesa; agenciamento; (des)reterritorialização.

\section{Introdução}

De acordo com um dos mitos fundadores do cristianismo - ao separar Deus a porção seca chamada terra da porção de águas chamada mar -, o Criador organiza o estado caótico das matérias, demarcando tanto os espaços humanos quanto o tipo de atividade a ser desenvolvida em cada área, estabelecendo os primeiros territórios e fronteiras para a ação das criaturas. Como herança paterna divina, dota os homens com racionalidade para dominarem e governarem todos os outros viventes, distinguindo, assim, nesse plano organizado, quem seriam os sujeitos das ações e os objetos delas. Conforme fora previsto, os homens tornaram-se não apenas dominantes de outras espécies, mas também exploradores e descobridores dos espaços previamente limitados, agindo sobre eles, desenvolvendo técnicas para arar a terra, para pescar e navegar sobre os mares, criando relação de extrema intimidade e significado com esses elementos, a ponto de transformarem-nos em lugar, que, segundo Oliveira (2014, p. 12) é o local onde "se pode habitar e desenvolver sentimentos e emoções". A carga simbólica de sentidos que se atribui involuntariamente a esses lugares de vivências é o que Oliveira chama de "sentimento topofílico ou topofóbico", já que "não importa se é um local natural ou construído, a pessoa se liga ao lugar quando este adquire um significado mais profundo ou mais íntimo". (OLIVEIRA, 2014, p. 12)

Assim, entende-se que os povos que habitam "a borda" ou "margem" de dois espaços distintos participam da diluição das fronteiras de um lugar e outro, por exemplo, aqueles que vivem em terras circunvizinhas ao mar, por estabelecerem relações corporais, afetivas e ritualísticas mais diretas e profundas com o ambiente marítimo, interagindo rotineiramente com ele, criam um tipo de extensão do seu território como se ele também integrasse a zona de vizinhança onde se constituem como hecceidades ${ }^{1}$. Especialmente nessas regiões em que o mar e terra se entrecruzam e se deixam compor, o desejo surge como força de afeto agenciadora desse processo em que as pessoas também se associam de múltiplas maneiras: coabitando lugares distintos, fluindo para múltiplas atividades e direções ao mesmo tempo e, em alguns casos, tornando-se elementos de borda em novas relações e configurações de vida, sempre no entremeio das circunstâncias e existências promovidas numa erupção de redes de acoplamentos. Partindo dessa reflexão e da verificação de que o mar é um dos elemento que também compõe a poesia portuguesa fato facilmente verificável pela grande incidência em que sua imagem aparece nela -, dialogaremos com a filosofia de Deleuze e Guattari para discutir processos de (des)subjetivação, entendendo a escrita e a leitura literárias como possibilidades de desterritorialização não apenas geográfica, mas também do escritor do leitor, permitindolhes criar outros tipos de reterritorializações com essa peça-chave com a qual se unem. 


\section{Aspectos teórico-metodológicos}

Deleuze e Guattari (2004) afirmam ser em meio a conexões heterogêneas que o plano do desejo ou "plano de imanência" se constitui, que as vontades escapam dos coletivos para se tornarem fluxos de potências produtivas. Assim, seja por meio da pesca, do lazer, da navegação ou do ritual religioso, o mar é o elemento que desperta desejo, que propulsiona o rompimento de macroestruturas de aspecto geográfico, econômico e social, transformando-as por meio de fluxos pelos quais múltiplas linhas de fuga escapam em direção a um estado descentralizado e caótico, no qual o interior de um elemento se constitui na relação com o exterior de outro e o exterior do outro com o interior daquele com que se reuniu ${ }^{2}$, não havendo distinção entre os componentes que se agenciam porque se tornam todos eles extensões num nível molecular, já que criam uma zona afetiva de pertença, de cuja interação o mar e os humanos saem marcados reciprocamente. Em outras palavras, isso significa que, quando as conexões entre os elementos humanos, físicos, biológicos e afetivos se relacionam com o mar, elas podem se metamorfosear por um processo de desejo, compondo o plano de imanência em que a vivência é ressignificada para quem delas participa, não havendo diferenciação entre sujeito e objeto porque tais categorias não existem nesse plano, à medida que, pela capacidade de afetarem e de serem afetados, se avizinham molecularmente dentro da coletividade de que fazem parte. Deleuze e Guattari (2004) chamam essa dessubjetivação de "hecceidade", ou seja, uma potência produtora de individuações sem sujeito, enquanto corpo em afeto com o mundo, num nível impessoal e intensivo.

É todo o agenciamento em seu conjunto individuado que é uma hecceidade; é ele que se define por uma longitude e latitude, por velocidades e afectos, independentemente das formas e dos sujeitos que pertencem tão somente a outro plano. É o próprio lobo ou o cavalo, ou a criança que param de ser sujeitos para se tornarem acontecimentos em agenciamentos que não se separam de uma hora, de uma estação, de uma atmosfera, de um ar, de uma vida. (DELEUZE; GUATTARI, 1997b, p. 49-50.)

De acordo com a proposta deleuzo-guattariana, a hecceidade é um corpo molecular abstrato de partículas e múltiplas linhas de forças: afetos, velocidades e lentidões coletivos, o qual se modifica infinitamente por uma latitude e longitude. Trazendo esses dois conceitos da cartografia, já desterritorializados do sentido original por Espinosa ao falar sobre as dimensões do corpo, Deleuze e Guatari (1997b) os reterritorializam para descrever a composição da hecceidade, sendo a longitude dela a parte "extensiva" desse "corpo molecular", por isso referente ao "conjunto dos elementos materiais que lhe pertencem sob tais relações de movimento e repouso, de velocidade e de lentidão", e a latitude dela a parte "intensiva", daí ser relacionada ao "conjunto de afectos intensivos (...) sob tal grau de potência” (DELEUZE; GUATTARI, 1997b, p. 47). Ressaltamos que tais afetos intensivos se formam em blocos nômades de forças que escapam dos corpos molares que se reúnem, constituindo potência para a desestratificação e dessubjetivação das individualidades modeladas pelos sistemas hierárquicos. São os afetos ativos e passivos que indicam o que se pode ou não fazer, mesmo num agenciamento individuado. Pode-se dizer, dessa forma, que afeto não é "um sentimento pessoal, tampouco uma característica", mas "a efetuação de uma potência de matilha, que subleva e faz vacilar o eu" (DELEUZE; GUATTARI, 1997b, p. 17). Por isso, os afetos, as velocidades e lentidões se abstraem dos corpos e enunciados em agenciamento para se tornarem blocos de energias outras, promovendo devires. Em suma, as hecceidades são produções fluídas que tais potências manifestam no 
nível "micrológico" do plano de imanência, em oposição aos sujeitos estruturados no nível "macrológico" do plano de organização, em cuja forma o senso comum parece colar uma identidade ${ }^{3}$. Além disso, pode-se dizer, inclusive, que os conceitos de "unidade", "pessoa" e "ego", que estão articulados ao conceito de sujeito, representam "modelização", "rostidade" e "padronização", pois, "[e]m síntese, a subjetividade seria um dentro (região) do Fora, ou antes, uma 'invaginação', uma dobra do Fora" (SAVAZZONI, 2012, p. 63), já a hecceidade seria conseguir produzir movimentos outros: desdobramentos e redobras, pressupondo a composição da singularidade marcada pela multiplicidade e pela diferença concomitantemente, ao inventar novos modos de se lançar à vida num processo constante de tornar-se, de devir, fora do encapsulamento individual,

\begin{abstract}
[t]anto que cada indivíduo é uma multiplicidade infinita, e a Natureza inteira uma multiplicidade de multiplicidades perfeitamente individualizada. O plano de consistência da natureza é como uma imensa máquina abstrata, no entanto real e individual cujas peças são agenciamentos ou os indivíduos diversos que agrupam, cada um, uma infinidade de partículas sob infinidade de relações mais ou menos compostas. (DELEUZE; GUATTARI, 1997b, p. 35.)
\end{abstract}

Como já sugerido anteriormente, as produções de subjetividades, geralmente, são perpassadas por linhas de forças desejantes numa relação simbiótica e rizomática. Os dois adjetivos aqui são trazidos de termos da biologia (simbiose e rizoma), de onde o sentido é (des)reterritorializado pela filosofia de Mil Platôs, podendo ser usados, portanto, para designar as alianças entre natureza, homem e máquina (simbiose), que se fazem multiplamente sem hierarquia e centralidade (rizoma). Para elucidarem um movimento de produção de subjetividade contrário ao que o desejo produz, Guattari e Rolnik (1996) trazem-nos a metáfora do funcionamento de uma máquina para criticarem os agenciamentos pré-determinados do sistema capitalista, entendidos como "de uma natureza industrial, maquínica, essencialmente, fabricada, modelada, recebida, consumida" (GUATTARI e ROLNIK, 1996, p. 25). Porém, diferentemente desse modo de produção subjetiva, pretendemos nos debruçar sobre as composições descentradas, múltiplas, que se fazem continuamente, cujo funcionamento depende não apenas de elementos de "natureza infra-humana, infrapsíquica, infrapessoal", mas também de outros de "natureza extrapessoal e extraindividual" (GUATTARI; ROLNIK, p. 31), baseadas no desejo como força que provoca linhas de fuga dessas produções subjetivas enquadradas socialmente. De qualquer forma, entendemos que a subjetividade se produz e se molda no social, por agenciamentos diversos (maquínicos e de enunciação ${ }^{4}$ ), porém é tomada e vivida pelas pessoas, na forma de seu desejo, em suas existências particulares - em sua singularidade - , por meio de relações simbióticas com objetos, lugares e seres, tendendo, pois, a oscilar em dois extremos:

\footnotetext{
Uma relação de alienação e opressão, na qual o indivíduo se submete à subjetividade tal como a recebe, ou uma relação de expressão e criação, na qual o indivíduo se reapropria dos componentes da subjetividade, produzindo um processo que eu chamaria de singularização. (GUATTARI; ROLNIK, 1996, p. 33.)
}

Guattari e Rolnik (1996) questionam os modos de aprisionamento do homem às máquinas abstratas, mais especificamente, na contemporaneidade, ao capitalismo e suas formas de formatação das subjetividades, pois os agenciamentos coletivos de enunciação funcionam diretamente nos agenciamentos maquínicos dos corpos, impondo práticas e regras de como se deve amar, trabalhar, falar, viver por meio dos componentes discursivos. 
Sobre a relevância do desejo nas experiências cotidianas, a questão é melhor pensada e explicada por Deleuze e Guattari quando compõem uma "cartografia" dos processos desejantes que nos atravessam. Segundo Savazzoni:

\footnotetext{
Assim, a cartografia esquizoanalítica consiste numa "dupla análise", tanto dos processos de estratificação, significação e subjetivação (entendidos aqui como sinônimos), como das linhas de fugas que são traçadas e os fluxos desejantes que as percorrem. (SAVAZZONI, 2012, p. 73.)
}

Segundo os dois estudiosos da esquizoanálise, o Inconsciente Maquínico é uma usina produtora de desejo cuja potência energética constitui a nós e às nossas realidades (no plural porque são várias); entretanto, não tem sujeito nem objeto, portanto é impessoal porque faz parte do "coletivo", anseia sempre estabelecer conexões e transformações, é um elemento de vida própria em um corpo abstrato que funciona em um sistema "aberto", "ativo" e "molecular". Ao discutirem a atuação do sistema capitalista nesse processo, criticam o recalcamento, o aprisionamento e a estratificação do desejo pelo sistema, manipulando a produção desejante e criativa, fabricando indivíduos normatizados por padrões globais de consumo, serializados numa rotina maquínica de trabalho e de vida, mas rostificados por uma identidade aparentemente individual, que se marca por meio da repetição, do hábito, conferindo, assim, a sensação ilusória de liberdade. Esse é o grande truque do sistema: manter o desejo preso para a produção de subjetividades que as instituições de poder consigam disciplinar.

Isso não significa que as subjetividades sejam atravessadas exclusivamente ou pelas "linhas" de um segmento mais rígido, "molar", ou pelas de outro mais flexível, "molecular", mas sim que ora um grupo delas consegue se marcar mais em determinadas circunstâncias. Na verdade, segundo Deleuze e Guattari (1996), por essas linhas serem inseparáveis e coexistirem, somos perpassados sempre por elas "ao mesmo tempo". Sendo assim, por mais endurecido que seja um sistema binário estratificado, há algo que vaza dessa segmentaridade molar para atingir ao conjunto, abrindo fissuras, capazes de liberar o desejo para algo novo, de maneira construtiva e inventiva. Da mesma forma, por mais que se tente fugir dos estratos e das formas ou quebrar as funções, há algo que tapa as linhas de fuga e captura o desejo. Portanto, chega-se aqui à conclusão que, na predominância da linha molar, o desejo se estratifica, podendo ser, inclusive, destruído e aniquilado quando se chega ao extremo da fixidez, pois está inserido num sistema hierarquizado de funções delimitadas e formatadas dentro de um "plano de organização". Já na predominância da linha molecular, ele sobrevive, se desestratifica, se liberta, cria conexões, rizomas, fluxos de intensidade que percorrem nossos mapas existenciais, daí a necessidade de que faça parte de um plano "aberto" de "zonas de intensidades contínuas" ou "plano de consistência" e sempre "pensado "fora' do sujeito" (SAVAZZONI, 2012, p. 83). Por fim, na predominância das linhas de fuga, como sugerem Deleuze e Guattari (1995 e 1997), processos desejantes inerentes a elas explodem as estraficações e/ou as territorializações que impedem o desejo de fluir, liberando-o para participar de um plano abstrato e mais caótico ainda que o plano de consistência, onde se encontra com multiplicidades de forças nômades, desorganizadas e intensas, as quais se transformam em conexões incessantes que não têm começo nem fim, produzindo "devires" ou "mudanças de natureza" no pensamento, nas ações, nos afetos, nas artes. Todavia, entendemos que por mais desterritorializadas que se tornem as possibilidades de composição subjetiva, os agenciamentos sempre estabelecem outras territorialidades, que se desfazem novamente, por novos processos desejantes. 
Partindo, pois, deste quadro teórico, será de nosso interesse, no desenvolvimento deste estudo, analisar como o desejo, ao mesmo tempo que desterritorializa, maquina também agenciamentos com o mar e provoca um devir-escritor e devir-leitor em quem se torna fluxo na composição da máquina marítima. Sendo também atravessados pelo desejo de participar de uma conexão territorial com Portugal, escolhemos, portanto, cartografar em sua poesia moderna alguns processos de desejo e de composição de hecceidades, primeiramente por ser um território adjacente ao mar cujas influências e expressividade observamos fortemente na literatura (e nas artes portuguesas em geral) e, depois, em função do forte diálogo dos espaços da cidade de Lisboa com a poesia por meio de monumentos e referências constantes aos versos. Por conseguinte, a partir dos estudos teóricos realizados para uma pesquisa maior, percebemos, na análise dos materiais, surgir a composição de um processo de agenciamento de corpos entre poetas/leitores, espaço (Portugal/Lisboa), coisa (mar) e enunciados (produzidos nas poesias) de maneira involuntária, o qual nos interessamos em discutir e interpretar. Ao mesmo tempo, a coletânea de poemas do corpus - do qual aqui trouxemos uma amostra de dois deles - será como um mapa de leitura que nos permitirá encontrar ângulos distintos acerca dos espaços marítimos portugueses, bem como "fazer entradas diferentes, e, portanto, realizar incursões e interpretações sob pontos de vista também diversos". (ANDRADE; ALMOZARA, 2016, p.47.)

Enfatizamos, nesse estudo, que traçaremos nossas próprias "entradas" e percurso de leitura a partir dos dispositivos (poemas) com os quais nos agenciarmos, porém sabemos que eles permitem outros a serem encontrados pelos leitores, já que tais materiais são fluxos de desejo que escapam de memórias para se converterem em arte literária, cuja opacidade e porosidade linguísticas são características que possibilitam a construção de múltiplos sentidos. Pierre Nora (1993) aborda bem a questão da necessidade de os seres humanos criarem esses "lugares de memória" para "armazenarem" as lembranças que não querem esquecer, os quais chamamos de arquivos, posto que "não existe memória espontânea" (idem, p. 13). Andrade e Almozara (2016, p. 47) explicam também, a partir do conceito trazido de Foucault (2004), que os arquivos que são constituídos pelas memórias podem ser vistos por dois olhares: o dos documentos e o dos monumentos. O primeiro "projeta-se como algo imóvel, imutável, institucionalizado, portanto, morto" (ANDRADE; ALMOZARRA, 2016, p. 47) e fechado, já o segundo é atualizado, ressignificado e vivificado a cada movimento de "leitura", conceito esse que as duas autoras estendem também aos objetos artísticos contemporâneos, cujo sentido se constrói na interação. Dessa maneira, diz-se que qualquer objeto artístico se configura como um acontecimento dentro da perspectiva estética, uma vez que traz tanto uma memória (repetível) do passado quanto algo inédito (enquanto novidade do momento), em oposição ao arquivo-documento, cujo sentido parece estagnado.

Segundo Rancière (2009, p. 12), "as coisas da arte são as coisas do pensamento", logo da memória, que carregam elementos antigos e acrescentam inovações. Assim, os artistas conseguem atualizar os agenciamentos das experiências particulares e coletivas que lhe provocaram afeto, injetando essa mesma potência produtiva nas poesias, pinturas e esculturas citadina que criam, tornando-as mapa de leitura do passado pelos inúmeros vestígios nelas encontrados do diálogo humano com o espaço marítimo, de maneira nova e plurissignificativa, seja na instância de sujeitos ou hecceidades. Ao analisar a potência das artes, Deleuze e Guattari sugerem que os artistas (em especial os escritores) se descolam da maioria das outras peças humanas no sentido de que conseguem, por meio da criação, sentir e experimentar a realidade de um plano de fora, virtual, em estado de devir, porque se permitem estar à margem das experiências humanas, em que as vivências estão em

IPOTESI, JUIZ DE FORA, v.21, n.1, p.13-27, jan./jun. 2017 
constante movimento e atualização, e, no encontro com mecanismos de natureza variada, emitem partículas de movimento e repouso, os quais formam zonas de vizinhança a partir de vetores que carregam, pois, assim, se "despessoalizam" em singularidades anônimas e móveis numa potência de matilha para produzirem devires outros, aproximando-se daquilo que podem, criando em vez de reproduzirem (DELEUZE; GUATTARI, 1977; 1997). Assim, depois de desterritorializados, os artistas podem se reinserir na máquina social, reterritorializando-se, ou, em outras palavras, produzindo "revoluções moleculares", que serão sentidas no macromecanismo, pois aprenderam como fugir ao padrão molar ao qual a maioria das pessoas se mantêm presas.

Fazendo uma articulação disso com os estudos de Rancière (2009), entende-se que a estética artística (assim como a política) é um modo tanto de provocar movimentos e abrir linhas de fuga no sensível quanto de construir a visibilidade dos acontecimentos. Para ele, as formas de comunicação criam um universo de energia, de ideias e de vontades, o que relacionamos aos fluxos que Deleuze e Guattari propõem em sua teoria. Neste aspecto, o artista seria, assim:

\begin{abstract}
aquele que viaja nos labirintos e subsolos do mundo social. Ele recolhe os vestígios e transcreve os hieróglifos pintados na configuração mesma das coisas obscuras ou triviais. Devolve os detalhes insignificantes da prosa do mundo sua dupla potência poética e significante. Na topografia de um lugar ou na fisionomia de uma fachada, na forma ou no desgaste de uma vestimenta, no caos de uma exposição de mercadorias ou de detritos, ele recolhe os elementos de uma mitologia. E, nas figuras dessa mitologia, ele dá a conhecer a história verdadeira de uma sociedade, de um tempo, de uma coletividade. (RANCIÈRE, 2009, p. 36.)
\end{abstract}

Competiria ao artista, portanto, promover encontros entre a arte e o mundo. Porém não entendemos que ele proponha "verdades", como sugere o autor, já que qualquer composição de determinados aspectos do mundo ou de paisagens específicas não conseguem se livrar da contaminação de um olhar sobre dado fenômeno que se altera a partir de uma perspectiva. Segundo Michel Collot ,estudioso francês de literatura e de paisagem, esta última "é um espaço percebido, ligado a um ponto de vista" e um fenômeno complexo que "envolve três componentes: um local, um olhar e uma imagem" (COLLOT, 2013, p. 17). Sendo "configurada, ao mesmo tempo, por agentes naturais e por atores humanos em interação constante é, portanto, uma coprodução da natureza e da cultura em todas as suas manifestações" (COLLOT, 2013, p. 43).

Por conseguinte, a paisagem não é mais considerada como um conjunto de formas a reproduzir, mas como um reservatório de forças no qual o artista pode retirar o que produz uma obra, ao mesmo tempo dependente e diferente de seu ambiente. (COLLOT, 1993, p. 45.)

Portanto, a paisagem é um acontecimento perceptivo, já que surge no encontro entre o interno e o externo, metamorfoseando-se a cada momento. Não é nem algo interior nem algo exterior, mas uma relação que se dá no entremeio dos dois, o que parece dialogar com o conceito deleuziano de dobra, enquanto plissado de um movimento de articulação entre termos, o qual permite entender a relação do mundo conosco e a nossa com ele, isto é, a produção de subjetividades e modos de subjetivação enquanto territórios existenciais assinalados por uma historicidade. Discutindo o conceito de "dobra" de Foucault, Deleuze (2005) explica que todas as relações e agenciamentos que estabelecemos com o exterior nos constituem como se o lado de fora se dobrasse e se curvasse para formar em nós um

IPOTESI, JUIZ DE FORA, v.21, n.1, p.13-27, jan./jun. 2017 
forro subjetivo, "que se escava e se desenvolve segundo uma dimensão própria" (DELEUZE, 2005, p. 107), ou seja, as dobras seriam "as cavidades, plissados e campos que só existem em relação àquelas mesmas forças, linhas, técnicas e invenções que as sustentam" (ROSE, 2001, p. 180) Num dobramento contrário, a paisagem também é marcada pelos plissados que o elemento humano deixa nela.

Em outras palavras, pode-se dizer que a paisagem se constitui e assume determinadas características em função dos afetos que se produzem entre o olhar, o lugar e a imagem num determinado tempo, ou seja, é o agenciamento extensivo e intensivo desses elementos que comporão as características de sua longitude e latitude, territorializando-se conforme a intensidade afetiva expanda ou diminua suas conexões. Tal como a "subjetividade" é uma relação de forças com o fora, a paisagem é uma relação de forças com o "dentro", afetando e sendo afetada reciprocamente. "Mesmo estando centrada no ponto de vista de um sujeito, a paisagem não deixa de estar situada num espaço e num devir coletivos" (COLLOT, 2013, p. 53). De acordo com Merleau-Ponty (1994, p. 40 apud COLLOT, 2013, p. 47), "é preciso que os relevos, as linhas de força dessa paisagem induzam uma sintaxe profunda, a um modo de composição e de narração, que desfaçam e refaçam o mundo e a linguagem usuais". Assim, as paisagens são maquinadas por essas multiplicidades de forças que se cruzam, produzindo devires dos quais a literatura pode participar, ao produzir arquivos-monumentos e ao ser (re)lida, compondo o que Rose (2001) chama de "máquina literária". Conforme as peças que se combinam e a intensidade das forças de desejo nas ligações, as paisagens se alteram e incorporam as novidades numa territorialidade. Na literatura portuguesa, é muito constante encontrarmos o mar como coparticipante na formação das paisagens, principalmente na poesia. Além de também estabelecer uma conexão que nos afeta, ela serve de registro para entendermos como os portugueses devêm com o mar.

Em virtude da brevidade deste artigo, deter-nos-emos ao estudo de dois poemas, partindo da perspectiva de Foucault para pensar o poema como parte de um arquivomonumento. Partindo dessa proposta, é imprescindível começarmos, "desterritorializando" a função do olhar para sentir a intensidade da produção que se cria aqui coparticipativamente, cuja prioridade não é a análise linear do corpus, mas, sim, a experiência de sentir, pelas trilhas da leitura, as vibrações e as explosões, ocasionadas pelas linhas de fuga desse agenciamento de enunciados.

Começando pelas linhas de fuga do texto, Derrida (2001), ao abordar a questão dos arquivos "vivos", afirma que eles se transformam no encontro com o leitor, visto que são abertos a novas reescritas e releituras, sugerindo maleabilidade do tecido textual. Isso acontece pelas fissuras que se abrem na/ pela escrita, frestas pelas quais quem escreve e quem lê pode passar, permear, deslocar e rearranjar, uma vez que não é possível encontrar uma verdade oculta por trás deles, pois nenhum sentido discursivo é transparente, mas, sim, construído pelas aberturas linguísticas, que deixam correr múltiplas linhas de fuga, dentre elas as de caráter semântico, sintático, simbólico, histórico dos enunciados acessados (que não deixam de constituir agenciamentos coletivos de enunciação), e pelas novas inscrições que essas linhas permitem fazer sobre eles, ou seja, é essa porosidade textual que admite a pluralidade de sentido numa troca de intensidades com os conhecimentos de mundo do leitor.

Já com relação às linhas de fuga do pesquisador-leitor, ainda de acordo com Derrida (2001), tratando sobre o papel dos historiadores, reconhece-se que o processo de seleção de determinados arquivos em detrimento de outros também abre "lacunas", "apagamentos", "descartes", "esquecimentos", pois todo recorte de materiais naturalmente faz isso. Logo, tal incumbência "organizadora" e "guardiã" de arquivos, que teriam os

IPOTESI, JUIZ DE FORA, v.21, n.1, p.13-27, jan./jun. 2017 
antigos "arcontes", ao mesmo tempo que restringe o desejo de criar novas conexões com os textos descartados, cria as fissuras necessárias para que linhas de fuga apareçam e o desejo escape.

Como pesquisadores-leitores, ainda, compilamos um material determinado de estudo e análise, porém ansiamos que o leitor rompa as estratificações e territorializações que por ventura encontre, evadindo-se pelas linhas de fuga do caminho para descobrir muitos outros poemas que aqui não tivemos tempo de inserir, mas que também fazem parte da rede de leitura das paisagens marítimas portuguesas e se agregam à nossa proposta de criar um mapa de leitura em movimento pelo qual possamos percorrer em reciprocidade. Então, para tecermos uma parte das malhas que darão conexão e mobilidade aos poemasmonumentos, selecionamos aqueles que parecem ter potência para configurar conosco o nosso território de pesquisa, no qual processos de (des)subjetivação sejam discutidos a partir de novas reterritorializações com o mar.

Quanto mais entradas aos textos os leitores propuserem e quanto maior o repertório trazido, mais linhas de fuga aparecerão, tornando extensivas e intensivas as imagens mentais para quem vê, numa composição cartográfica de múltiplas linhas de enunciados poéticos e de corpos em coletividade de sensações, impressões, lembranças, experiências, imagens, afetos. Assim, a ideia é tecer uma narrativa em rede, sem hierarquização nem atribuição de valores aos poemas, em que todos os discursos poéticos sejam igualmente relevantes, desempenhando o papel de fios condutores entre as peças que configurarão devires no encontro com o mar. Baseando-nos na perspectiva cartográfica de Deleuze e Guattari, os poemas podem ser considerados fluxos de experiências, intensidades afetivas, mapas de palavras que oferecem ao leitor a possibilidade de ele percorrer e se hibridizar com a potência de relatos compostos a partir do encontro de hecceidades com o mar. Se, segundo Michel Collot "é o olhar que transforma o local em paisagem" sendo não apenas "ato estético, mas também de pensamento" (COLLOT, 2013, p. 18), cabe ao olhar daqueles que são parte dessa composição ressignificar os contornos das paisagens que lhes afetam quando encarnados nas diferentes funções que assumem, - poeta e leitor - dando lugar, logo em seguida, à formação de hecceidades, que se constituem a partir dos fluxos dos diferentes elementos que ali se encontram.

Por outro lado, as fissuras do escritor se abrem nas linhas de fuga do processo criativo por meio do qual o poeta se transforma em máquina desejante, ao emitir energia, afetos e intensidades, deixando o desejo percorrer zonas de vizinhança onde, por algum motivo, afete e seja afetado, não havendo distinção dos elementos do conjunto, num plano de indiscernibilidade onde produza um devir. Dessa forma, ser um escritor nômade é movimentar-se pela língua diariamente, reinventando usos para palavras desgastadas, fugindo às regras e à escrita representativa para investir em expressões mais sugestivas e sinestésicas, inovando na sintaxe de modo que descubra um jeito nunca antes experimentando, criando, assim, sua língua (DELEUZE; GUATTARI, 1997a). Em virtude desse processo de deslocamento semântico e de metamorfose linguística, o escritor despese da sua individualidade para se tornar fluxo em meio aos agenciamentos que se estabelecem em cada obra, compondo com eles um corpo sem órgãos desfeito de funções pré-estabelecidas, cuja potência transborda nos textos por meio de reconfigurações do pensamento, das relações e da existência. Por isso, as produções literárias são sempre uma enchente de sentidos inacabados, que extravasam as fissuras da escrita a cada nova conexão de leitura.

Já a fenda da paisagem marítima é a linha do horizonte, por meio da qual imagens diferentes se abrem ou se ocultam do olhar conforme o movimento que se faça. Para Collot (2013, p. 83), “o horizonte é uma linha imaginária que não encontramos em mapa algum, 
mas, ao mesmo tempo, seu traçado depende de fatores físicos e objetivos"), de limite "móvel, aberto ao apelo de alhures" (COLLOT, 2013, p. 34).

\section{Mar: um lugar de encontros}

Portugal é um desses lugares no qual o mar é uma extensão do país e da própria cultura, um traço da portugalidade. Assim, na tentativa de estabelecerem posse e familiaridade, demarcando a área, denominam-se as águas do rio que banha toda costa de Lisboa e deságua no oceano com o nome próprio de Tejo. Relph (2014, p. 22) explica que "nos conectamos com o mundo por meio de lugares que geralmente possuem nomes ou uma identidade específica", sendo eles microcosmos onde nos relacionamos com o mundo e o mundo se relaciona conosco. Já Deleuze e Guattari (1997b) entendem os nomes próprios como "algo que é da ordem do acontecimento, do devir ou da hecceidade" (p. 44), não sendo eles a designação individualizada de um sujeito ou lugar, mas a transformação de um substantivo genérico ou específico em "agente de um infinitivo" composto por "velocidades e afectos". Sendo assim, a palavra "mar", dentro da cultura portuguesa, tem sentido de um nome próprio pelas sensações, acoplamentos, devires, promovidos em função do desejo que os une. Quer seja por referência à capital portuguesa chamada Lisboa quer pelo rio de nome Tejo ou mesmo pela palavra "mar", tais nomes configuram paisagens culturalizadas de vivências compartilhadas.

Por isso, enfatizamos que, neste estudo, a literatura portuguesa - em especial o gênero poema - será, sim, um dispositivo de entrada ao território cujos espaços geográficos desejamos penetrar e percorrer, entendendo alguns dos agenciamentos enunciativos e de corpos que surgem na composição de suas paisagens. Além disso, desde o advento das mídias impressas, na história moderna, a circulação dessa literatura foi impulsionada ainda mais, correndo o mundo em livros por meio dos quais qualquer leitor pode adentrar, desenvolver relações afetivas com os elementos configurados na paisagem e se transformar. Por questão de familiaridade linguística, histórica e cultural, a relação que nós, brasileiros, estabelecemos com ela é ainda mais próxima.

A ideia que Deleuze (1997a) traz de literatura é a de algo informe, um fluxo que escapa do talento do escritor e se deixa escorrer pelas fissuras das estruturas sociais, que faz verter desejos e modos outros de sentir a vida, de maneira que o leitor escorra para outras zonas de vivência, permitindo-lhe conectar-se a experiências com as quais jamais teria contato sem a leitura, de maneira que cada nova conexão com o texto seja um novo encontro de espaços e afetos. Vivenciado com essa potência, entendemos que tal dispositivo possa romper com as estruturas e estratos que nos cristalizam, arrancando-nos do pensamento formatado para nos atirar em direção a outros fluxos de pensar e sentir a existência, a ponto de nunca mais sermos os mesmos. Da mesma maneira, nós, como leitores de Deleuze, atribuímos sentido ao pensamento filosófico dele quando também buscamos na memória as vezes em que nos agenciamos aos livros que lemos, sendo arrebatados por fluxos mútuos de desejo: os que já foram impregnados na narrativa por meio do processo criativo (incluindo a emissão de energia, afetos, intensidades produzidos pela máquina-escritor, associados a determinado uso da língua a partir de um gênero), e os que criamos, acoplando-os a ela, quando nos deixamos irromper pelos nossos deviresleitor. Portanto, segundo Deleuze (1997a), não se pode separar a escrita da ideia de devir, visto que ela é processo, promoção de abertura nos modelos, criação de linhas de fugas e possibilidade de descolamento do escritor da maioria das pessoas, já que promove acontecimentos cujos resultados são imprevistos, portanto únicos a cada leitura. Assim, é justamente o inacabamento que torna a produção rica, à medida que a escrita se refaz constantemente em cada conexão de leitura, de espaço e de afeto, estando em contato

IPOTESI, JUIZ DE FORA, v.21, n.1, p.13-27, jan./jun. 2017 
constante com o fora. E o escritor, nesse momento, parece buscar um estado e linguagem nômades (em que os signos se inscrevem no corpo e no território).

Além desses aspectos, Deleuze acrescenta que há devir em algo quando existe uma conexão rizomática que verte desejos, que produz outros modos de ser, de viver e de se relacionar intensivamente em coletividade molecular $\mathrm{O}$ mar surge, nestes poemas, como uma força vetorial que propulsiona a escrita, a leitura e os afetos, uma energia desejante que flui ao encontro dos poetas e dos leitores, que se mistura e se confunde com eles, que pulsa na literatura e deixa a literatura pulsar em seus arredores, Assim, é de nossa intenção verificar os tipos de (des)montagens ou assemblages que podem surgir nestas relações entre os diversos elementos que se cruzam e permeiam as regiões adjacentes ao mar e ao Tejo, entendendo que forças vetoriais dão origem aos devires-mar. Lembramos que Deleuze e Guattari não falam sobre devir-mar, porém é um conceito que criamos à luz da teoria deles e achamos propício desenvolver para pensar nesses agenciamentos recorrentes na expressão poética portuguesa. Queremos dizer que, nesse sentido, o devir-mar não é a imitação da forma aquosa da entidade molar que conhecemos, mas uma relação de movimento e repouso que coloca os humanos numa zona de indiscernibilidade com ela, onde podem experimentar modos de individuação por meio dos quais se produzem intensidades de um mar molecular em si mesmos.

Embora os poemas aludam a espaços físicos costeiros comuns, tais regiões não são engessadas numa forma constante, porque a configuração do cenário geográfico e natural se renova por meio de elementos que se agregam à composição dele e, pouco tempo depois, desaparecem. A percepção dos poetas sobre esses locais é distinta não apenas pelo movimento organizacional dos componentes externos que se renovam na assemblage, mas por se transformarem em hecceidades, possibilitando uma nova ordenação e funcionamento da engrenagem paisagística. Rose (2001) explica que a palavra assemblage, traduzida como agenciamento, tem sentido de montagem, arranjamento ou combinação de peças para formar um novo objeto. Desta forma, é possível pensar que cada devir-mar é a combinação de elementos heterogêneos que proporciona uma experiência afetiva junto às aguas. Nesse momento, o poeta se dessubjetiva de quem é para sentir a potência da paisagem na qual se configura um agenciamento de corpos, mentes, desejos e enunciados. Por outro lado, por meio da escrita, a memória do acontecimento pode ser renovada e vivificada a cada leitura. Enfim, essas paisagens perceptivas acabam ganhando materialidade simbólica nas poesias, ao comporem uma rede de mapas poéticos pelos quais podemos percorrer da maneira como quisermos.

O mar permeia não apenas as moléculas da poesia portuguesa desde o período medieval $^{5}$, mas também tem relação de dobra com o próprio olhar português sobre si enquanto nação, já que se torna um elemento de composição molecular e históricoeconômica, tanto por ter sido responsável, no mito de origem, pela vinda do ancestral mais antigo do povo, o marinheiro errante Ulisses, que fundou a capital portuguesa e deu a "Lisboa o seu nome, Ulisseum, transformado depois em Olisipo" (GERSÃO, 2011, p. 34), quanto pela participação na história das grandes navegações. Esse lugar de memória e afeto é constantemente renovado pelas novas experiências que as peças humanas vão compondo à engrenagem.

Assim, nesta assemblage, propomos a navegar pelos poemas-mapas a partir de Mar I, de Sophia de Mello Breyner Andresen ${ }^{6}$, a fim de verificar como o devir-mar traz potência a quem dele participa:

Mar I

De todos os cantos do mundo

IPOTESI, JUIZ DE FORA, v.21, n.1, p.13-27, jan./jun. 2017 
Amo com um amor mais forte e mais profundo

Aquela praia extasiada e nua,

Onde me uni ao mar, ao vento e à lua. (ANDRESEN, 1990, p. 18.)

Observa-se que a escrita se converte em dispositivo para a cartografia de um desejo: unir-se "àquela praia". Em agenciamento com o papel (territorialização enunciativa), a poetisa deixa escorrer pelas frestas da repetição do advérbio de intensidade "mais" a potência "forte" e "profunda" do amor topofílico (desejo) que a propulsiona a escrever, revelando o surgimento de linhas de fuga na escrita - uma aberta pelo afeto ao se referir à região, assim como outra de melancolia - sugeridas pelo uso do pronome demonstrativo "aquela", e ampliada pelas trilhas da distância que a separa de lá. Mais do que retomar a potência perdida, é o encontro desfeito que ela quer recompor, portanto a separação dos componentes emperra o movimento e inibe a produção de um devir. As peças estão separadas precisando se unirem. Por isso ela precisa sair do plano molar de sujeito, onde é apenas um elemento fragmentado sem potência, para penetrar num nível molecular em que se agencie com o mar, o vento e a lua, compondo um devir-mar com eles. Portanto, o devir-mar só acontece na (des)reterritorialização.

Talvez ela precise voltar a se perder como fazia antes para se transformar subjetivamente em hecceidade e redescobrir um outro devir-mar, liberando as linhas de fuga do desejo. Talvez, ainda, a distância apareça como justificativa para a não união física por conta da dificuldade que se cria, ao longo dos anos, em se romperem estratificações. Dessa maneira, a única alternativa encontrada é recorrer ao plano da memória para configurar alguma potência de agenciamento. Collot (1993) sugere que, se somos afetados por algo na natureza, é por termos algo dela em nós que precisa ser descoberto, de maneira que isso implique uma "abertura da consciência ao fora" (COLLOT, 1993, p. 30). Assim, "de todos os cantos do mundo", somente naquela "praia extasiada e nua", a poetisa encontra na nudez e no extasiamento da paisagem algo de seu, ao passo que a natureza lhe confere potência necessária para escrever, formando-se, nessa relação, o que Deleuze chama de dobra: sendo o fora um reflexo do dentro e o dentro um reflexo do fora. Portanto, pela escrita ela consegue estabelecer essa relação com os outros corpos e elementos da natureza, buscando na composição a possibilidade de expressar esse desejo não estratificado. "O próprio corpo não é senão uma dobra na carne do mundo, graças ao qual este acede à consciência" (COLLOT, 1993, p. 38). Portanto, a partir de tal integração, o pensamento-paisagem sobre o qual nos fala Collot (1993, p. 29): "é um pensamento partilhado do qual nos falam o homem e as coisas". Desta forma, energizada por esse pensamento-paisagem e pelos afetos desenvolvidos por esse lugar de recordação, a poetisa entra um devir-escritor para percorrer as bordas da lembrança de seu devir-mar. A partir dessa relação simbiótica, a poetisa, que continua um indivíduo, se "combina", nessa máquina desejante, com o mar, que continua mar, avizinhando-se de potências com as quais se monta temporariamente. É a escrita que lhe permite registrar a memória da vez em que se tornou um mar molecular em intensidade, não em forma, ou seja, uma hecceidade molecular em experiência de devir. Como não se constitui devir com substâncias molares, há a necessidade de ela tornar-se molecular. Daí serem os nômades, as mulheres, os loucos, por que não os poetas, que conseguem desempenhar os processos de linha de fuga.

\section{Mar português}

Ó mar salgado, quanto do teu sal

São lágrimas de Portugal!

Por te cruzarmos, quantas mães choraram,

IPOTESI, JUIZ DE FORA, v.21, n.1, p.13-27, jan./jun. 2017 
Quantos filhos em vão rezaram!

Quantas noivas ficaram por casar

Para que fosses nosso, ó mar!

Valeu a pena? Tudo vale a pena

Se a alma não é pequena.

Quem quer passar além do Bojador

Tem que passar além da dor.

Deus ao mar o perigo e o abismo deu,

Mas nele é que espelhou o céu. (PESSOA, 2002, p. 48)

Nesse outro poema, a interação entre os portugueses e o mar produz outro movimento de dobra: o mar fica com o plissado da portugalidade, tornando-se um corpo territorial de memórias ${ }^{7}$. Em "Mar Português", Fernando Pessoa reconhece na salinidade do oceano as lágrimas dos ancestrais heroicos que se aventuraram pelas águas para ampliar as rotas comerciais e territoriais do país, bem como as dos parentes deles que aguardaram o regresso dos que jamais voltaram. Portanto, esse atributo de ser português é entendido como a marca de pertencimento com a qual nação contaminou todo o Atlântico, não podendo nunca ele perder essa característica de sistema molar já incorporada.

Tendo sido, anteriormente, coparticipante das Grandes Navegações, o mar tornouse o símbolo desses agenciamentos coletivos de enunciação que a história guarda, relembra e dissemina. Na tentativa inicial de dominação do mar, as peças humanas precisaram se engrenar num movimento coletivo ativo de estudos, a fim de adequarem as embarcações conforme a área oceânica a ser percorrida ou mesmo o formato, tamanho e o movimento das velas, de acordo com o funcionamento das correntes de vento. Logo, não seria possível cruzarem o oceano sem entrarem em devir com ele. Assim sendo, somente quando a coletividade alcançou a unidade de esforços, num movimento sincrônico de desejos, as máquinas humanas, os dispositivos náuticos e o mar desenvolveram o "código" que lhes faltava e o devir-mar aconteceu porque os portugueses aprenderam como fazer isso: desterritorializando-se subjetivamente ao se tornarem hecceidades e sendo parte da nova reterritorialização dos componentes. Aqui, o poeta aparece na zona de vizinhança da coletividade de seu povo, pois, não tendo participado das empreitadas, carrega a memória de sua gente e se hibridiza nos afetos desenvolvidos por ela, produzindo um agenciamento coletivo de enunciação por meio do qual se torna elemento de borda para cartografar as vivências que tiveram.

Mapeando os fluxos de pensamento e de desejo portugueses, bem como as rotas marítimas para ampliação de um territorium ${ }^{8}$ além da firmeza da terra, o poema se energiza com a potência do devir-mar e rompe as estruturas lógicas do pensamento, preferindo o uso de figuras de linguagem por meio das quais o mar se humaniza na interlocução com a nação, apontando ela o processo de extrema dor que é ter o organismo transformado em um corpo sem órgãos. Aquilo que, a princípio, eram organizações sociais e familiares teve de encontrar maneiras outras de vivência e de existência após as tentativas de cruzamento do oceano, já que, ao estabelecer conexão entre as naus e o mar, o desejo maquínico provocou desestratificações e dessubjetivações para que, então, acontecesse o devir. As vontades particulares dos navegantes, os papeis familiares que exerciam e a individualidade deles foram desfeitos pelo sofrimento da dessubjetivação para se rearranjarem como múltiplas forças de hecceidades, agenciadas pelo desejo intensivo nacional de cruzar o oceano. Por terem arrancado seus órgãos e aberto mão de suas singularidades, os portugueses se tornaram um corpo sem órgãos, uma máquina desejante coletiva que soube aplicar movimentos e velocidades para se engrenar em devir-mar. Por outro lado, as mulheres - as "mães" e as "noivas" - e as crianças - filhos - por serem IPOTESI, JUIZ DE FORA, v.21, n.1, p.13-27, jan./jun. 2017 
minorias, que viviam à borda das estruturas, já manejavam o escape pelas linhas de fuga, constituindo devires.

Se "valeu a pena" essa transformação dos homens e do país? A própria voz nacional ressoa nos versos: "Tudo vale a pena/ Se a alma não é pequena". Sugerindo que Portugal abandonou os órgãos para não ser fechado nas particularidades, as quais the tirariam a potência de uma alma grande, ou seja, a natureza do devir-descobridor que perderia. Assim como que "Quem quer passar além do Bojador/ Tem que passar além da dor", entendido o Cabo da Costa marítima do Saara Ocidental como lugar da transformação, de devir, em que o limite oceânico foi colocado em xeque pelos portugueses, para que o devir-mar estabelecido fosse relembrado na memória coletiva e nos arquivos-documentos da história, quem deseja ultrapassar o horizonte de qualquer paisagem ou vencer outros tipos de limites, precisa encontrar as linhas de fuga do percurso, a fim de que se torne parte das simbioses, afetividades, intensidades, transformações que o perpassam.

\title{
Algumas (in)conclusões
}

Dessa maneira, entende-se que, conforme a combinação e a posição das peças nos agenciamentos de corpos e de enunciados, um tipo de devir aparece mais nos fluxos do discurso. Especificamente nos dois poemas percorridos, veem-se surgir três devires interagenciados: o devir-escritor, o devir-mar e o devir-leitor, ora um se marcando mais que outros em diferentes momentos desse trajeto de leitura, a despeito de, no processo de conhecimento do território de pesquisa, serem igualmente importantes. Assim, nas paisagens literárias, o devir-mar acontece quando o elemento humano se agencia com as águas salgadas, dessubjetivando-se para se transformar em hecceidades, ao criar zonas de vizinhança em que se compartilham desejos, ações, afetos, memórias por meio de uma relação de afinidade com ele. Nestes mesmos textos, a lembrança da potência do devir-mar instiga a escrita e a produção de um devir-escritor, apesar de nem sempre ser possível por meio dela retomar toda energia do acontecimento finalizado. Apesar disso, esse devir permite entender a vida por perspectivas ainda mais intensivas, de maneira que a produção do texto se torne um fluído vital para a sociedade. Por fim, o devir-leitor também é uma possibilidade de dessubjetivação humana e desterritorialização do olhar. Assim, por meio dos afetos que os poemas despertaram nós, estabelecemos conexões com eles de forma intensiva e colaborativa, tanto criando malhas que lhes dessem sentido quanto cartografando possíveis relações estabelecidas entre as hecceidades e as paisagens formadas;. Propomos, assim, as nossas perspectivas às quais os demais leitores têm a possibilidade de agregar modos outros de olhar. Portanto, pode-se dizer que, do agenciamento entre leitor, poeta e poemas, um devir-leitor se estabelece na relação.

\section{Becoming-sea: assemblages in Portuguese poetry}

\begin{abstract}
This paper will discuss how the Portuguese are crossed by affections and desires that connect them to the sea, bringing some examples from Portuguese poetry that accomplish this relationship, where subjective and geographical territories are submitted to a process of (de)reterritorialization in search of different ways to compose collective assemblages of bodies and enunciation, producing a becoming-sea process.
\end{abstract}

Keywords: becoming-sea; portuguese poetry; assemblage; (de)reterritorialisation. 


\footnotetext{
" Doutorada na UNICAMP (Linguística Aplicada); professora-pesquisadora na PUC-Campinas, no curso de Letras e no PPG do Mestrado stricto sensu Linguagens, Mídia e Arte, do Centro de Linguagem e Comunicação. Possui vários artigos publicados, tais como "Os (não) limites entre o público e o privado em tempos de convergência midiática", na Revista Cadernos de Letras da UFF, v.27, 2017; e "EFL Brazilian Teachers in the hypermodern world: prêt-à-porter subjects, social media and discourse", em Trabalhos em Lingüística Aplicada, v. 55, 2016.

${ }^{* *}$ Graduada em Letras (Português e Inglês) pela PUC-Campinas, professora da rede pública de Campinas e mestranda no PPG do Mestrado stricto sensu Linguagens, Mídia e Arte (LIMIAR), sob a orientação da profa. Dra. Eliane Righi de Andrade.

${ }^{1} \mathrm{O}$ conceito será explicado posteriormente.

2 Aprofundaremos a discussão quando tratarmos sobre o conceito de "dobra".

${ }^{3}$ Guattari e Rolnik (1996) aproximam a identidade aos esquemas sociais de conduta, de pensamento, de afetos e busca de sentidos. O que denominam como singularização, por outro lado, seriam os processos particulares que o sujeito cria para se relacionar com o mundo, por meio de forças e relações de aliança. Enquanto o primeiro é um conceito de referenciação, o segundo é um modo de existência.

${ }^{4}$ Falaremos sobre os agenciamentos maquínicos e de enunciação.

5 "Ondas do mar de Vigo" de Martim Codax é uma cantiga de amigo medieval em que o mar aparece como confidente do desespero amoroso.

${ }^{6}$ Sophia de Mello Breyner Andresen foi uma poetisa portuguesa de destaque no século XX, cuja temática constante das obras é o mar, provavelmente pela vivência em lugares como a Praia da Granja, em Campo Alegre, a cidade de Lagos, no Algarve, e viagens pelo Mediterrâneo e Mar Egeu.

${ }^{7}$ Assman (2011) traz a ideia de que marcas físicas do corpo, como cicatrizes, são memórias de eventos passados. Portanto, no poema, o sal do mar pode ser entendido como uma marca dessa relação com Portugal.

${ }^{8}$ De acordo com Haesbaert (2012), o vocábulo latino deriva da palavra "terra", designando um pedaço de solo inserido numa jurisdição político-administrativa.
}

\section{REFERÊNCIAS}

Sophia de M. B. Mar. $2^{\mathrm{a}}$ ed. Lisboa: Caminho, 2001.

ASSMAN, Aleida. Espaços da Recordação: Formas e Transformações da Memória Cultural. Tradução Paulo Soethe (Coord). Campinas: Editora da Unicamp, 2011.

COLLOT, Michel. Poética e Filosofia da Paisagem. Tradução de Ida Alves. Rio de Janeiro: Editora Oficina Rachel, 2013.

GUATTARI, Félix; ROLNIK, Suely. Micropolítica: Cartografias do Desejo. $4^{\mathrm{a}}$ ed. Petrópolis: Vozes, 1996.

DELEUZE, Gilles. Crítica e Clínica. Tradução de Peter Pal Pelbart. São Paulo: Ed. 34, 1997a.

DELEUZE, Gilles. Foucault. Tradução de Claudia Sant'Anna Martins; revisão da tradução Renato Ribeiro. São Paulo: Brasiliense, 2005.

DELEUZE, Gilles; GUATTARI, Félix. Kafka: Por Uma Literatura Menor. Tadução de Júlio Castañol Guimarães. Rio de Janeiro: Imago Editora LTDA, 1977.

DELEUZE, Gilles; GUATTARI, Félix. Mil Platôs: capitalismo e esquizofrenia, vol. 01. Tradução de Aurélio Guerra Neto e Célia Pinto Costa. Rio de Janneiro: Ed. 34, 1995. 
DELEUZE, Gilles; GUATTARI, Félix. Mil Platôs: capitalismo e esquizofrenia, vol. 03. Tradução de Aurélio Guerra Neto, Ana Lúcia de Oliveira, Lúcia Cláudia e Suely Rolnik. Rio de Janeiro: Ed. 34, 1996.

DELEUZE, Gilles; GUATTARI, Félix. Mil Platôs - Capitalismo e Esquizofrenia, vol. 04. Tradução de Suely Rolnik. São Paulo: Ed. 54, 1997 b.

DELEUZE, Gilles; GUATTARI, Félix. O Anti-Édipo - Capitalismo e Esquizofrenia. Tradução de Joana Moraes Varela e Manuel Maria Carrilho. Lisboa: Assírio e Alvim, 2004.

DERRIDA, Jacques. Mal de arquivo: Uma Impressão Freudiana. Tradução de Claudia Moraes Rego. Rio de Janeiro: Relume Dumará, 2001.

FOUCAULT, Michel. A arqueologia do saber. Rio de Janeiro: Editora Forense Universitária, 2004. FOUCAULT, Michel. Ética, Sexualidade, Política. (Col. Ditos e escritos, vol. V). Rio de Janeiro: Forense Universitária, 2006.

GERSÃO, Teolinda. A cidade de Ulisses. Porto: Sextante, 2011.

HAESBAERT, Rogério. O Mito da desterritorialização: do "fim dos territórios" à multiterritorialidade. $7^{\mathrm{a}}$ ed. Rio de Janeiro: Bertrand Brasil, 2012.

MERLEAU-PONTY, Maurice. Le problème de la parole. In: Résumés de Cours. Paris: Gallimard, 1968.

NORA, Pierre. Entre história e memória: a problemática dos lugares. Revista Projeto História. São Paulo, v. 10, p. 7-28, 1993.

OLIVEIRA, Lívia de. O Sentido de Lugar. In: MARANDOLA JR, Eduardo; HOLZER, Werther; OLIVEIRA, Lívia de (Org.). Qual o Espaço do Lugar . São Paulo: Perspectiva, 2014. p. 3-16.

PESSOA, Fernando. Mensagem. Coleção a obra-prima de cada autor. São Paulo: Martin Claret, 2002.

RANCIÈRE, Jacques. O Inconsciente Estético. Tradução de Mônica Costa Netto. São Paulo: Editora 34, 2009.

RELPH, Edward. Reflexões sobre a Emergência, Aspectos e Essência de Lugar. In: MARANDOLA JR, Eduardo; HOLZER, Werther; OLIVEIRA, Lívia de (Org.). Qual o Espaço do Lugar . $1^{\text {a }}$. ed. São Paulo: Perspectiva, 2014. p.17-32.

ROSE, Nikolas. Inventado nossos eus. In: SILVA, Tomaz Tadeu da (Org.). Nunca fomos humanos. Belo Horizonte: Autêntica, 2001. p.17-204.

SAVAZZONI, César Augusto. Subjetividade e devir à luz da filosofia de Deleuze e Guattari: contribuição para uma psicologia. 2012. Dissertação - Faculdade de Filosofia, Ciências e Letras, Universidade de São Paulo, Ribeirão Preto, 2012. 